\title{
Effect of thermal treatment on the interfacial shear toughness of an aluminium composite laminate
}

\author{
C.M. Cepeda-Jiménez ${ }^{\mathrm{a}, *}$, P. Hidalgo ${ }^{\mathrm{a}}$, M. Pozuelo $^{\mathrm{b}}$, O.A. Ruano ${ }^{\mathrm{a}}$, F. Carreño ${ }^{\mathrm{a}}$ \\ a Department of Physical Metallurgy, CENIM, CSIC, Av. Gregorio del Amo 8, 28040 Madrid, Spain \\ ${ }^{\mathrm{b}}$ Department of Materials Science and Engineering, University of California, E-V 2122D, 410 Westwood Plaza, \\ Los Angeles, CA 90095, USA
}

\section{A R T I C L E I N F O}

\section{Article history:}

Received 7 September 2009

Received in revised form 9 December 2009

Accepted 9 December 2009

Keywords:

EBSD

Aluminium alloys

Thermomechanical processing

Interfacial toughness

\begin{abstract}
A B S T R A C T
The microstructure and mechanical properties in the interface region of a multilayer composite laminate based on $\mathrm{Al}-\mathrm{Zn}(\mathrm{Al} \mathrm{7075)}$ and $\mathrm{Al}-\mathrm{Cu}(\mathrm{Al} \mathrm{2024)}$ ) alloys have been mainly characterized by EBSD and shear tests. It is shown that varying solution heat treatments affect the microstructure of the constituent aluminium alloys in the bonding region and, as a consequence, the interfacial mechanical properties. The increase in the solution treatment time improves the interfacial toughness of the multilayer aluminium laminate due to higher intrinsic toughness of the constituent aluminium alloys.
\end{abstract}

(c) 2009 Elsevier B.V. All rights reserved.

\section{Introduction}

Advanced composite materials can be developed (in bulk form) with strength and toughness properties far superior to those of their individual constituents [1].

Hot roll bonded multilayer composite materials based on highstrength aluminium alloys have been processed providing a good combination of both high mechanical strength and ductility, i.e., fracture toughness [2,3]. Roll-bonding is a solid phase welding process, where the bonding is established by plastic deformation of the metals to be bonded [4]. In hot-rolled aluminium multilayer composites, bonding occurs by fracturing of the surface alumina on the layers since the oxide has a much lower ductility than aluminium, and then flowing the aluminium through the fractured alumina regions. The bond quality is influenced by a number of interdependent parameters such as temperature, pressure, degree of reduction and contact time (roll speed) [5,6].

The interfacial properties have been shown to greatly affect the mechanical behaviour of composite laminates [7,8], because interfaces are numerous and susceptible to decohesion and sliding [9]. Interface decohesion is most likely when the interface fracture resistance is relatively low and the adjacent substrates have a high yield strength. The latter condition is important because sub-

\footnotetext{
* Corresponding author. Tel.: +34 91 5538900; fax: +34 915347425.

E-mail address: cm.cepeda@cenim.csic.es (C.M. Cepeda-Jiménez).
}

strate yielding tends to blunt the crack at the interface and thereby suppress nucleation of an interface crack [10].

Additionally, after undergoing heat-treatment procedures (solution, quenching and aging), the interfacial regions, where diffusion of the alloying elements occurs, exhibit significant changes in their mechanical properties [11,12].

In a previous work, a multilayer composite laminate based on $\mathrm{Al}$ 7075 and $\mathrm{Al} 2024$ alloys was developed by hot roll-bonding, resulting in a material with outstanding impact toughness. A detailed mechanical analysis is given in Ref. [3]. After processing, a T6 thermal treatment was carried out to generate an efficient and uniform dispersion of precipitates, especially nanosized $\mathrm{MgZn}_{2}$ in the high-strength Al 7075 alloy. The conditions of the T6 heat treatment involved solution treatment at $465^{\circ} \mathrm{C}$ for $30 \mathrm{~min}$, followed by rapid quenching in water and finally age hardening at $135^{\circ} \mathrm{C}$ for $14 \mathrm{~h}$.

The aim of this paper is to study the influence of different solution treatment conditions on the microstructure in the bonding zone, and to correlate it with the interfacial shear mechanical properties of this hot-rolled composite laminate. The microstructure contains a number of heterogeneities, which may contribute to both the localization of plastic flow and the initiation and propagation of failure. The evolution of the microstructure and the interfacial toughness measured by shear tests as a function of the solution heat treatment has been analyzed. The relationship between the microstructural features and the fracture behaviour are established from fractographic observations. 
Table 1

Chemical composition of the as-received aluminium alloys (atomic percent).

\begin{tabular}{|c|c|c|c|c|c|c|c|c|c|}
\hline Alloy & $\mathrm{Si}$ & $\mathrm{Fe}$ & $\mathrm{Cu}$ & Mn & $\mathrm{Mg}$ & $\mathrm{Cr}$ & $\mathrm{Zn}$ & $\mathrm{Ti}$ & $\mathrm{Ni}$ \\
\hline 7075 “D” & 0.05 & 0.04 & 0.74 & 0.01 & 2.89 & 0.13 & 3.05 & 0.04 & - \\
\hline 2024 “L” & 0.07 & 0.04 & 2.46 & 0.21 & 1.26 & 0.04 & 0.14 & 0.02 & 0.06 \\
\hline
\end{tabular}

\section{Experimental procedure}

\subsection{Materials and processing}

The multilayer composite laminate considered in the present study is based on eleven alternate layers of $\mathrm{Al}-\mathrm{Zn} 7075$ alloy (termed "D") and Al-Cu 2024 (termed "L"), which has been produced by hot roll-bonding and referenced in this work as ADL11. The composition in atomic percentage of the aluminium alloys is included in Table 1 and some mechanical properties are summarized in Table 2 . The rolling processing was carried out at $465^{\circ} \mathrm{C}$ in several passes of about $4-8 \%$ reduction per pass, with the sample being reheated at $465^{\circ} \mathrm{C}$ between series, accumulating a total reduction in thickness of 2.3:1, corresponding to an equivalent strain of $\varepsilon=0.95$ (according to the von Mises criterion). This temperature was selected to be the solution temperature for the 7075 aluminium alloy (D). Additional details about the processing are given elsewhere [3]. The composite laminate obtained was in the form of a plate, of about $10 \mathrm{~mm}$ in thickness, about $350 \mathrm{~mm}$ in length and about $60 \mathrm{~mm}$ in width. The average thickness of the aluminium layers in the ADL11 composite laminate was about $920 \mu \mathrm{m}$.

Due to the high temperatures employed during the processing and that the composite laminate was cooled slowly at room temperature, it was necessary to carry out after hot rolling, a heat treatment to improve the mechanical properties of the aluminium alloys included in the composite laminate. A post-rolling tempering at $175^{\circ} \mathrm{C}$ during $6 \mathrm{~h}$ was performed prior to the T6 treatment in order to restore some ductility, to decrease the driving force for recrystallization and to avoid the premature failure of the interfaces $[3,13]$. The heat treatment performed was the T6 treatment that has been deemed optimum for the $\mathrm{Al} 7075$ alloy. This heat treatment involves solution treating at $465^{\circ} \mathrm{C}$, followed by rapid quenching in water and finally age hardening at $135^{\circ} \mathrm{C}$ for $14 \mathrm{~h}$ [14]. The time required for the solution heat treatment at $465^{\circ} \mathrm{C}$ depends on the type of fabrication procedure, sample thickness and pre-existing microstructure. Thin products such as sheets may require only few minutes. In this study, solution treating times at $465^{\circ} \mathrm{C}$ between 2 and $30 \mathrm{~min}$ were considered.

\subsection{Microstructural determination}

The microstructure in the normal direction (ND)-rolling direction (RD) sections of the as-received alloys and the thermal treated aluminium multilayer composite was examined by electron backscattering diffraction technique (EBSD), in a scanning electron microscope. Particular focus has been paid to the analysis of the aluminium matrix grain structures in the bonding zone, grain boundary misorientations distribution and crystallographic textures. Acquisition of EBSD data was done using a JEOL JSM

\section{Table 2}

Mechanical properties of the as-received aluminium alloys. UTS: ultimate tensile strength; YS: yield point; HV: Vickers Hardness; T6: solution treating followed by quenching and finally age hardening; T3: solution treating followed by quenching, cold working and finally natural aging.

\begin{tabular}{llllc}
\hline Alloy & UTS $^{\mathrm{a}}(\mathrm{MPa})$ & YS $^{\mathrm{a}}(\mathrm{MPa})$ & HV & Elongation $^{\mathrm{a}}$ \%) \\
\hline 7075-T6 “D” & 545 & 475 & 188 & 8 \\
2024-T3 “L” & 457 & 333 & 138 & 16 \\
\hline
\end{tabular}

a Data provided by the alloy maker from tensile tests.
6500F equipment with field emission gun, equipped with a fully automatic HKL Technology EBSD attachment, operating with an accelerating voltage and working distance of $20 \mathrm{kV}$ and $15 \mathrm{~mm}$, respectively. The corresponding data processing was then carried out using HKL Channel 5 software. Microstructural investigations of the aluminium alloys in the bonding region were carried out on midthickness locations of the laminate material. Orientation mapping was performed on a rectangular grid with a step size of $0.35 \mu \mathrm{m}$ covering an area of 460 (along RD) $\mu \mathrm{m} \times 367$ (along $\mathrm{ND}) \mu \mathrm{m}$. A low-angle grain boundary (LAB) was defined by a misorientation between adjacent grains of $2^{\circ}<\theta<15^{\circ}$, and a high-angle grain boundary (HAB) was defined by $\theta>15^{\circ}$. $\mathrm{HAB}$ and LAB are shown as black and white lines, respectively, on the maps. The grain thickness is determined by the linear intercept method in the EBSD maps, counting only $\operatorname{HABs}\left(\theta>15^{\circ}\right)$.

\subsection{Interface mechanical properties}

\subsubsection{Microhardness test}

Microhardness measurements were carried out around the laminate interfaces with a Vickers indenter under loads of $100 \mathrm{~g}$ during $15 \mathrm{~s}$. Vickers microhardness values vs. distance to the interface were represented in order to observe the hardness gradient across the interface. The distance to the interface was measured from the indentation centre using image analysis software.

\subsubsection{Shear test}

To characterize precisely the mechanical properties of interfaces, which are the main responsible of the fracture mechanisms and the damage tolerance improvement of multilayer composites $[2,3]$, shear tests along them have been performed. Shear tests were carried out in a Servosis universal test machine at a cross-head rate of $0.005 \mathrm{~mm} / \mathrm{s}$, using specimens of approximate dimensions $10 \mathrm{~mm} \times 10 \mathrm{~mm} \times 3 \mathrm{~mm}$. The test was carried out by clamping the sample between two metal supports. The interface to be tested is located just outside the border of the tool and parallel to the load direction. Then, a square punch at a given gap distance is used to apply the shear load until failure of the interface. A scheme of the shear test performed was shown elsewhere [15]. The shear stress, $\tau$, and the shear strain, $\gamma$, are given by the expressions [16]:

$\tau=\frac{p}{a e}, \quad \gamma=\tan \alpha=\frac{d}{l_{\text {gap }}}$

where $a$ is the initial width of the sample, $e$ is the initial thickness of the sample, $p$ is the force applied on the sample, $d$ is the midspan displacement of the sample, $\alpha$ is the shear angle and $l_{\text {gap }}$ is the span length between the supports and the mobile punch, corresponding to $0.35 \mathrm{~mm}$ in this study. The interfacial fracture modes as a function of the different thermal treatments have been qualitatively assessed by analysis of SEM micrographs.

\section{Results and discussion}

\subsection{Microstructure}

The microstructure of the as-received aluminium alloys in the LT orientation (longitudinal-transversal) from EBSD measurements is presented in Fig. 1. The EBSD maps have been colour coded according to the inverse pole figure (IPF) shown in the inset, and the 

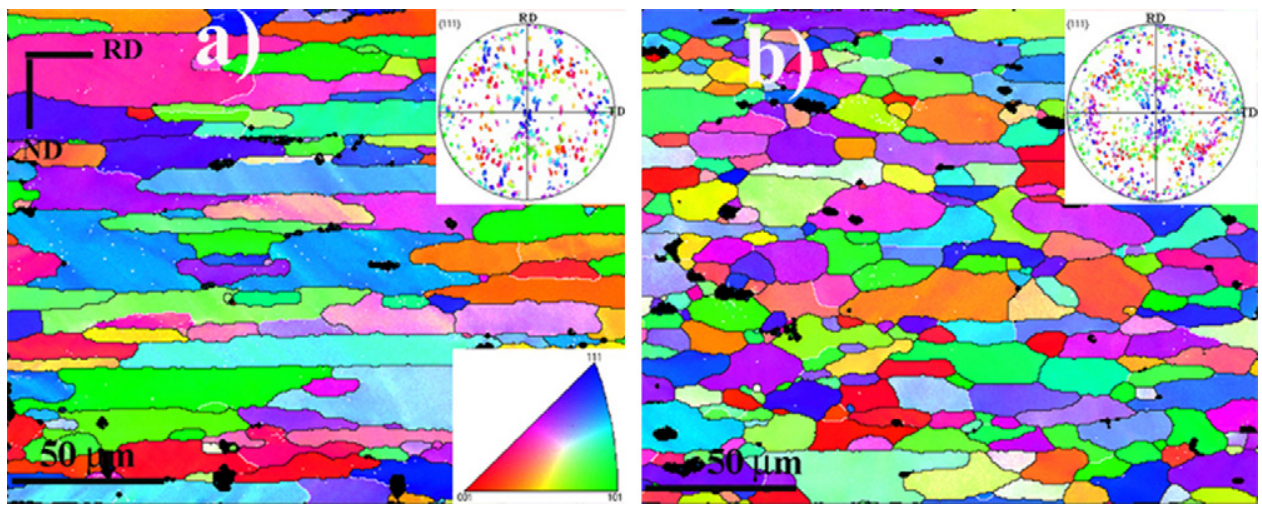

Fig. 1. EBSD maps of ND-RD sections and $\left\{\begin{array}{lll}1 & 1 & 1\end{array}\right\}$ pole figures of the as-received alloys: (a) Al 7075-T6 and (b) Al $2024-\mathrm{T} 3$.

colours represent the crystallographic orientations parallel to ND. Additionally, Table 3 presents the average grain thicknesses measured from the relative misorientation profile along vertical lines traced in the EBSD maps. Furthermore, the fraction of high-angle grain boundaries $\left(f_{\mathrm{HAB}}\right)$ for the as-received alloys and for the ADL11 composite laminate as a function of the different thermal treatments has also been included in Table 3. The as-received Al 7075 alloy (Fig. 1a) shows large grains that are elongated and flattened parallel to the rolling direction. The spacing between high-angle grain boundaries (HABs) in the normal direction was about $7.5 \mu \mathrm{m}$ and the $f_{\mathrm{HAB}}$ was $88 \%$ (Table 3 ).

On the other hand, the microstructure of the as-received $\mathrm{Al}$ 2024 rolled sheet in the LT orientation is presented in Fig. 1b. This microstructure consists of recrystallized grains that are less elongated than those for the $\mathrm{Al} 7075$. The HAB spacing in the normal direction for the as-received $\mathrm{Al} 2024$ alloy was about $7.4 \mu \mathrm{m}$ and the $f_{\mathrm{HAB}}$ was $92 \%$ (Table 3 ).

In addition, in both the as-received materials large insoluble iron-rich intermetallic particles and partially soluble constituent particles were observed to be randomly distributed. These particles are formed during alloy solidification and they are non-indexed in EBSD maps. These particles ranged in size from 0.5 to $5 \mu \mathrm{m}$. Previous works $[17,18]$ have reported three types of large intermetallic particles, $\mathrm{Al}_{7} \mathrm{Cu}_{2} \mathrm{Fe},(\mathrm{Al}, \mathrm{Cu})_{6} \mathrm{Fe}$ and $\mathrm{Mg}_{2} \mathrm{Si}$.

The $\left\{\begin{array}{lll}1 & 1 & 1\end{array}\right\}$ pole figures corresponding to the as-received aluminium alloys (inset of Fig. 1 ) show a weak $\beta$-fibre texture, characteristic of most rolled face-centred cubic metals [19]. In general, both the as-received aluminium alloys present grains of a wide range of orientations, highlighting the $S$ component $\left(\left\{\begin{array}{ll}12 & 3\end{array}\right\}\langle 634\rangle\right)$

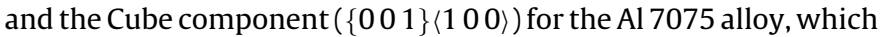
is associated with partially recrystallized structures [20].

Fig. 2a shows the EBSD map of the ADL11 composite laminate in the bonding region after processing plus a post-rolling tempering $\left(6 \mathrm{~h}, 175^{\circ} \mathrm{C}\right)$, termed in this study “as-rolled". Fig. $2 \mathrm{~b}-\mathrm{d}$ corresponds to the EBSD maps of the ADL11 composite laminate after postrolling tempering plus different $\mathrm{T} 6$ treatment conditions. These micrographs reveal the influence of time at solution temperature of $465^{\circ} \mathrm{C}$ on the microstructure evolution. Solution treatment times of 2 (Fig. 2b), 5 (Fig. 2c) and $30 \mathrm{~min}$ (Fig. 2d) have been considered. For all EBSD maps shown in Fig. 2 the top part corresponds to the Al 7075 alloy microstructure (D) and the bottom of the map corresponds to the $\mathrm{Al} 2024$ (L). The interfaces are located approximately in the middle of the maps, where non-indexed particles corresponding to alumina are observed homogenously and continuously distributed along the interface. During rolling, the aluminium matrix is able to deform plastically. In contrast, the alumina is brittle, and its response to the stress is fracturing. The aluminium occupying the opened spaces left by the fractured alumina and the diffusion of elements across these spaces is responsible for the bonding between clean metal surfaces. Additionally, large intermetallic particles randomly distributed in both alloys are non-indexed in EBSD maps.

The Al 7075 (D) in the as-rolled ADL11 composite laminate (Fig. 2a) presents a RD-aligned "pancake" microstructure separated by HABs (black lines). This elongated microstructure is retained after different thermal treatments (Fig. $2 b-d$ ). The boundaries in the normal direction are usually of low-angle character, and a subgrain structure is clearly observed (white lines). Accordingly, the fraction of high-angle grain boundaries $\left(f_{\mathrm{HAB}}\right)$ is decreased after the processing as shown in Table 3. The HABs spacing in the ND direction is reduced from $7.5 \mu \mathrm{m}$ in the as-received $\mathrm{Al} 7075$ alloy to $4.5 \mu \mathrm{m}$ in the as-rolled material (Table 3 ). The mean grain thickness for the Al 7075 alloy in the thermal treated ADL11 composite laminate shows a slight increase with increasing the solution treating time, from $4.1 \mu \mathrm{m}$ for solutioning time of $2 \mathrm{~min}$ to $4.6 \mu \mathrm{m}$ for $30 \mathrm{~min}$. This normal grain growth is associated with recovery from the non-equilibrium structure of the grain boundaries and partial annihilation of defects at grain boundaries and inside grains, and it is accompanied by partial relaxation of internal stresses [21]. On the other hand, the Al 2024 alloy in the as-rolled and treated ADL11 composite laminate (shown at the bottom of the maps in Fig. 2), presents a refined grain size and elongated microstructure only

Table 3

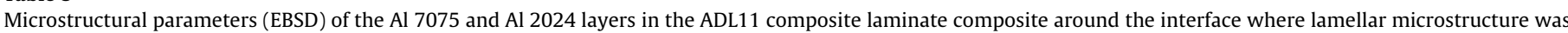

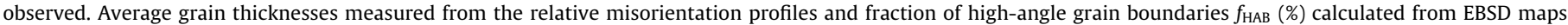
(Figs. 1 and 2).

\begin{tabular}{|c|c|c|c|}
\hline Temper & Grain thickness $(\mu \mathrm{m}) 7075$ & Grain thickness $(\mu \mathrm{m}) 2024$ & $f_{\mathrm{HAB}}(\%)$ \\
\hline As-received Al 7075-T6 & 7.5 & - & 88 \\
\hline As-received Al 2024-T3 & - & 7.4 & 92 \\
\hline As-rolled ADL $11+6 \mathrm{~h}-175^{\circ} \mathrm{C}$ & 4.5 & 6.1 & 57 \\
\hline $\mathrm{ADL} 11+6 \mathrm{~h}-175^{\circ} \mathrm{C}+2 \mathrm{~min}-465^{\circ} \mathrm{C}$ & 4.1 & 5.9 & 62 \\
\hline $\mathrm{ADL} 11+6 \mathrm{~h}-175^{\circ} \mathrm{C}+5 \mathrm{~min}-465^{\circ} \mathrm{C}$ & 4.3 & 5.0 & 59 \\
\hline $\mathrm{ADL} 11+6 \mathrm{~h}-175^{\circ} \mathrm{C}+30 \mathrm{~min}-465^{\circ} \mathrm{C}$ & 4.6 & - & 57 \\
\hline
\end{tabular}


close to the interface, because far from the interface the microstructure shows an abnormal grain growth, which spreads towards the interface with increasing solution treatment time. It is apparent that the constituent particles and precipitates present in the $\mathrm{Al}$ 2024 alloy are not able to pin the microstructure at high temperatures. Additionally, it is observed that grain migration activity is stopped at the interface. This can be attributed to the noticeable amount of alumina particles at the interface, which due to their nature and sizes are effective to hinder grain boundary migration across the bond interface.

Orientation data extracted from the EBSD maps have been also plotted as separate $\left\{\begin{array}{lll}1 & 1 & 1\end{array}\right\}$ pole figures (insets of Fig. 2 ). The asrolled composite laminate, especially the $\mathrm{Al} 7075$ alloy and the $\mathrm{Al}$ 2024 close to the interface, has developed a strong rolling texture with the highest intensity of the $S$ component $\left(\left\{\begin{array}{ll}12 & 3\end{array}\right\}\langle 634\rangle\right)$, as illustrated in the insets of Fig. 2a. The rolling texture is mostly retained after different thermal treatments in the Al 7075 alloy, and in the $\mathrm{Al} 2024$ alloy when an elongated microstructure is present (Fig. 2b-d). However, a comparison with the as-rolled state shows that the $\left\{\begin{array}{ll}0 & 01\end{array}\right\}\langle 100\rangle$ cube texture component is progressively increased with the solution treatment time. Simultaneously, a slight decrease in $\mathrm{S}$ and brass texture components occurs with increasing solution time.

The cube orientation has been reported as the recrystallization texture in many aluminium alloys [20,22], and thus is associated with a microstructure with lower degree of internal stresses and dislocations. Since the quenching and aging treatment have been identical for all T6 treated ADL11 composite laminate samples, the observed changes in the distribution of grain sizes, $f_{\mathrm{HAB}}$ and microtexture should be attributed to the different solution treatments considered.

Additionally, as expected, a diffusion zone is formed between the two materials as result of the good bonding, and thus a contin- uous transition from one aluminium alloy to the other is present. Diffusion of alloying elements leads to heat-treatable microstructures in the vicinity of the joining interfaces, which will determine also their mechanical properties. Fig. 3a-c shows concentration gradients in atomic percentage of $\mathrm{Zn}, \mathrm{Cu}$ and $\mathrm{Mg}$, respectively, in the interfacial regions of the ADL11 composite laminate as a function of the solution treating time. These are the main alloying elements in the present aluminium alloys. In general, the width of the region where significant element diffusion is observed is $60 \mu \mathrm{m}$ to both sides of the interface for the Zn diffusion (Fig. 3a), between 20 and $40 \mu \mathrm{m}$ for the $\mathrm{Cu}$ diffusion (Fig. 3b), and between 30 and $40 \mu \mathrm{m}$ for the $\mathrm{Mg}$ diffusion (Fig. $3 \mathrm{c}$ ). The extent of the $\mathrm{Zn}$ and $\mathrm{Mg}$ diffusion is not influenced by the solution treating time. In contrast, the $\mathrm{Cu}$ diffusion is wider for short solution treatments in the $\mathrm{Al} \mathrm{2024}$. This result is unusual, since larger diffusion distances with increasing solution treatment time to $30 \mathrm{~min}$ would be expected. Additionally, for a solution treatment of $30 \mathrm{~min}$, two different slopes for $\mathrm{Cu}$ diffusion across the interface are observed, being more pronounced in the $\mathrm{Al} 2024$ side. On the contrary, Cu diffusion gradient across the $\mathrm{Al} 7075$ from the interface seems similar for the three solution treating times considered, and as a consequence being independent of this parameter. Thus, the results show that the diffusion distance tends to be larger through the Al 2024 for the ADL11 composite laminate where fine grains are still observed around the interface (Fig. 2), which was solution treated for 2 and $5 \mathrm{~min}$. Accordingly, it is our contention that the short $\mathrm{Cu}$ diffusion distance observed for prolonged solution treatment $(30 \mathrm{~min}$ ) is due to the $\mathrm{Cu}$ atoms in solid solution are dragged towards the interface together with the abnormal grain growth produced in the $\mathrm{Al} 2024$ alloy. Furthermore, a higher $\mathrm{Cu}$ concentration is observed close to the interface (as showed by an arrow in Fig. 3b), than that in the bulk of the $\mathrm{Al} 2024$ alloy, suggesting $\mathrm{Cu}$ accumulation close to the interface.
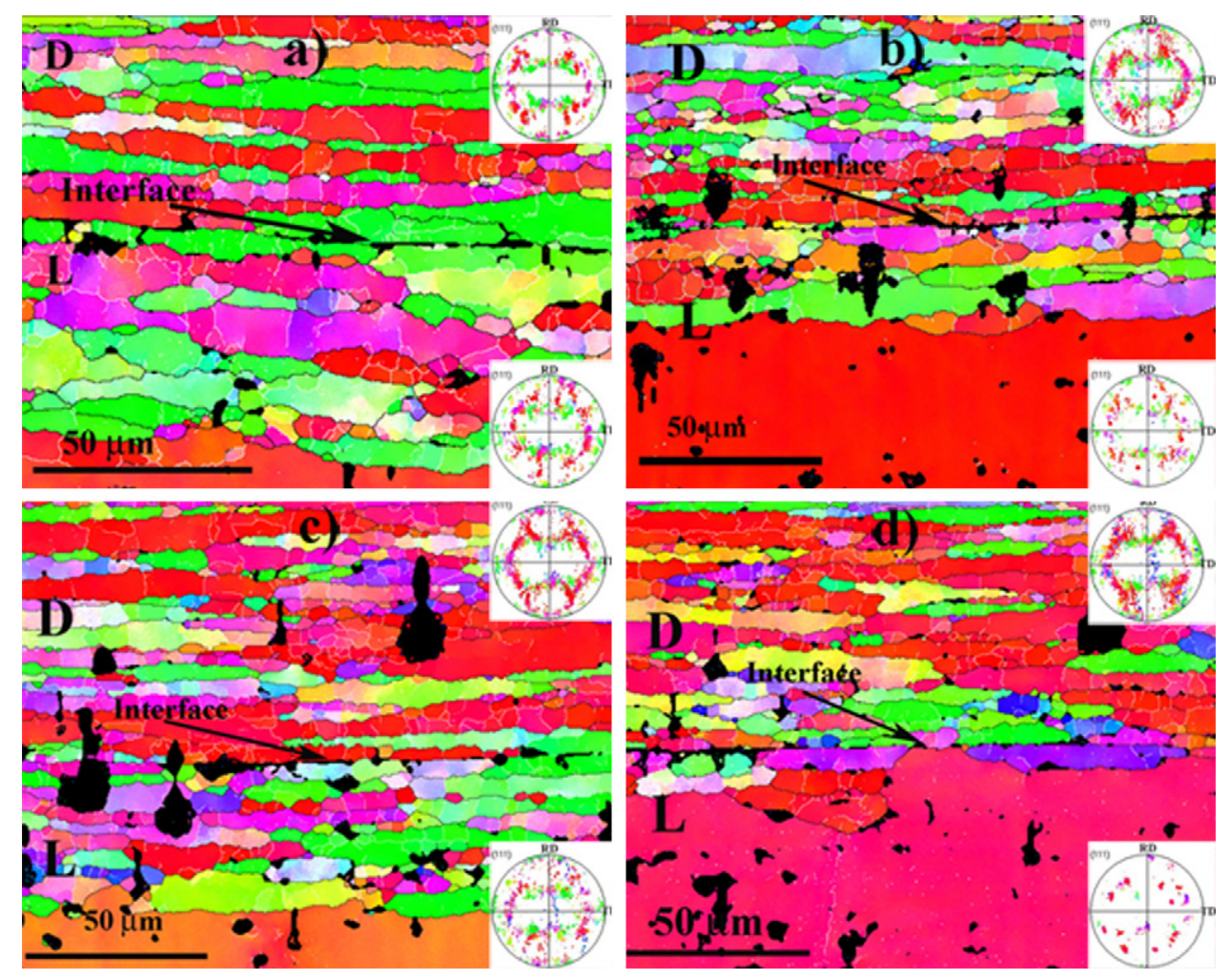

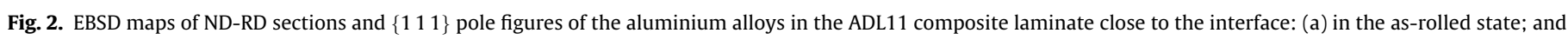

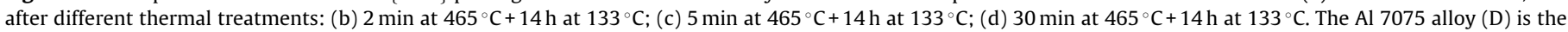
material at the top of the map and the $\mathrm{Al} 2024$ (L) is that at the bottom of the map. The black arrow indicates the interface location. 

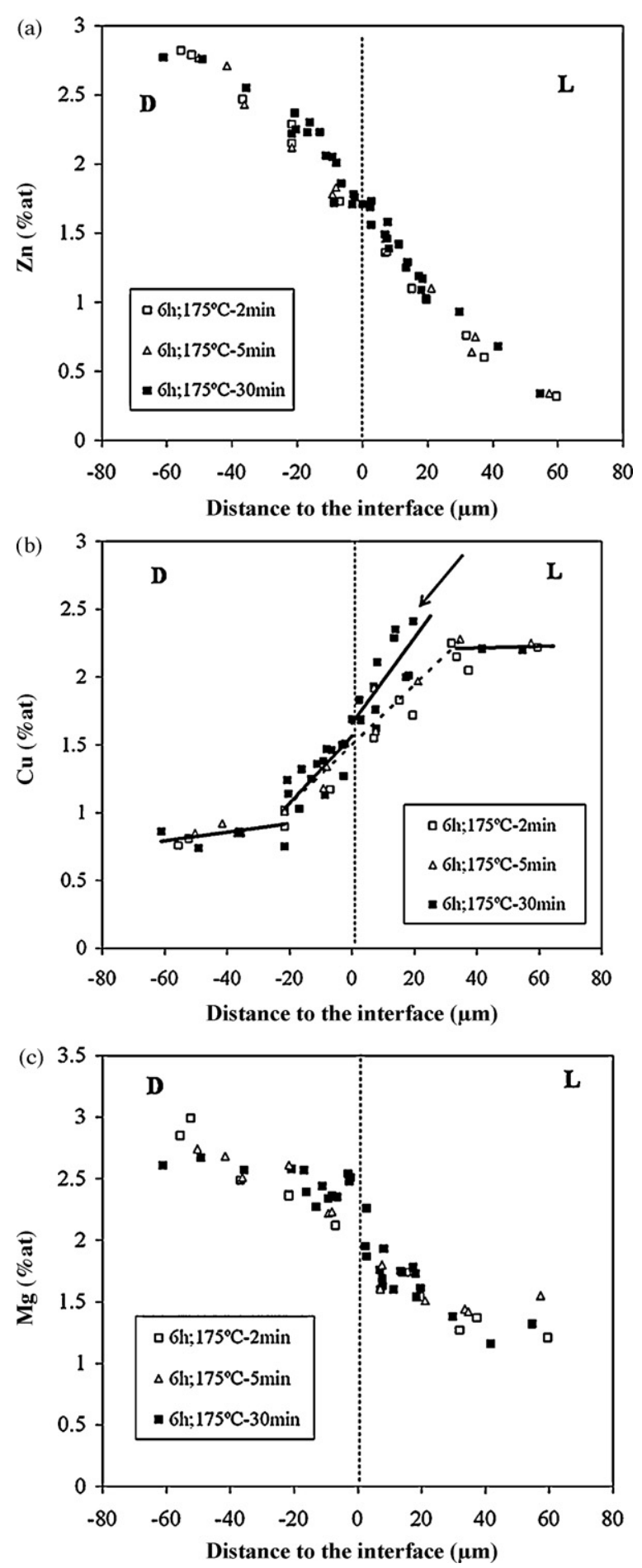

Fig. 3. Atomic percent of (a) $\mathrm{Zn}$, (b) $\mathrm{Cu}$, and (c) $\mathrm{Mg}$ composition across different interfaces (plotted in a single curve) in the ADL11 composite laminate after different thermal treatments, as a function of the distance to the interface.

This result is supported by previous studies about $\mathrm{Cu}$ segregation in $\mathrm{Al}-\mathrm{Cu}$ alloys at high temperatures $\left(480-500^{\circ} \mathrm{C}\right)[23,24]$, which reported that the $\mathrm{Cu}$ at high temperature $\left(460-500^{\circ} \mathrm{C}\right)$ segregates at grain boundaries, interfaces and dislocations, and second phase particle $\left(\mathrm{Al}_{2} \mathrm{Cu}\right)$ formation starts when these sites are saturated [23]. In addition, there was evidence that the fraction of the pinning phase $\left(\mathrm{Al}_{2} \mathrm{Cu}\right)$, present at boundaries between the fine grains, was approximately double than at the abnormal grain boundaries. The difference was thought to be due to the prefer-

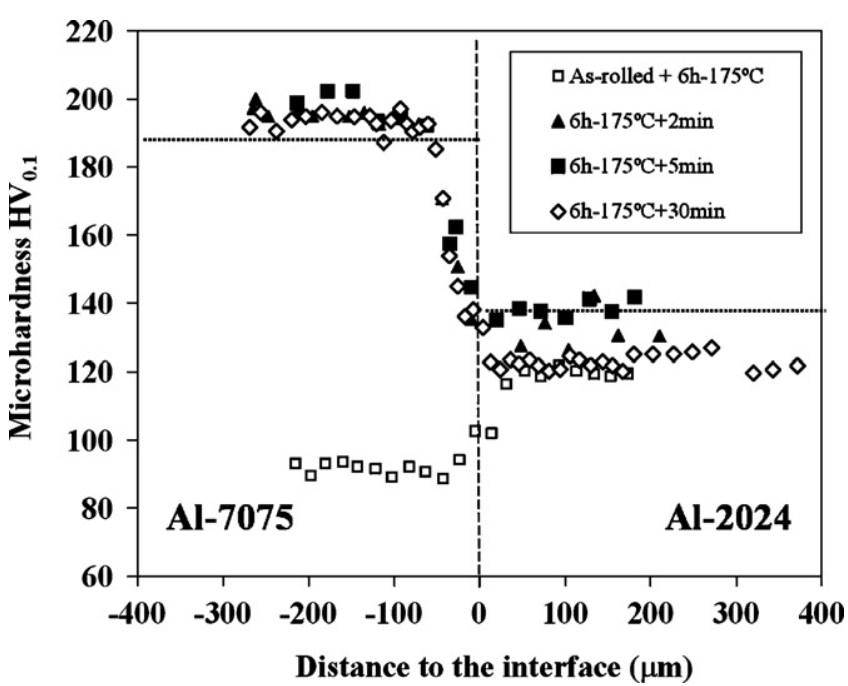

Fig. 4. Microhardness Vickers (100 g; $15 \mathrm{~s}$ ) across different interfaces (plotted in a single curve) in the ADL11 composite laminate after different thermal treatments, as a function of the distance to the interface.

ential retention of the pinning phase at nearly static boundaries [24]. Thus, these results would be in agreement with the $\mathrm{Cu}$ drag observed towards the fine grains close to the interface containing higher volume fraction of grain boundaries.

\subsection{Interface mechanical properties}

\subsubsection{Vickers microhardness}

Gradual element diffusion across the interface creates an area of age-hardenable compositions with significant changes in their mechanical properties, which were characterized by microhardness measurements as a function of different solution treating times (Fig. 4). It is well known that precipitation hardening is one of the most effective strengthening mechanisms to improve the strength in aluminium alloys [21]. Furthermore, a minimum element concentration is required for the formation of effective hardening $\mathrm{S}^{\prime}\left(\mathrm{Al}_{2} \mathrm{CuMg}\right)$ and $\eta^{\prime}\left(\mathrm{Zn}_{2} \mathrm{Mg}\right)$ precipitates across the interface [11]. The horizontal dotted lines in Fig. 4 indicate the microhardness value corresponding to the as-received Al 7075 (188HV) and $\mathrm{Al} 2024$ (138HV) alloys. The $\mathrm{Al} 7075$ layers in the asrolled composite laminate shows very low microhardness values of $92 \mathrm{HV}$, due to the high temperature employed during the processing $\left(465^{\circ} \mathrm{C}\right)$ and the slow cooling rate to room temperature. When a slow cooling rate is applied to the composite laminate after rolling, coarse precipitation occurs. This causes a decrease in yield and mechanical strength due to loss of solute available for fine scale hardening precipitation [25]. Furthermore, the post-rolling tempering produces an additional coarsening of precipitates and recovery of dislocations generated during the processing, decreasing even more the microhardness. All T6 treated samples subjected to different solutioning times show higher microhardness values than the as-received $\mathrm{Al} 7075$. On the other hand, only the shortest solution treatments ( 2 and $5 \mathrm{~min}$ ) produced similar microhardness values than that for the as-received Al 2024 alloy. The maximum microhardness of $199 \mathrm{HV}$ for the $\mathrm{Al} 7075$ far from the interface has been achieved for the T6 treated sample with 5 min of solution treatment. The solution time increase up to $30 \mathrm{~min}$ causes a slight decrease in microhardness for the Al 7075 alloy (194HV), due to the slight increase in grain size. On the other hand, the decrease in microhardness with the increase in solution time is more pronounced for the Al 2024 alloy (123HV). Previous works $[17,18,26,27]$ have reported that these alloys contains coarse intermetallic inclusions, rich in copper, as $\mathrm{Al}_{7} \mathrm{Cu}_{2} \mathrm{Fe},(\mathrm{Al}, \mathrm{Cu})_{6} \mathrm{Fe}$, 

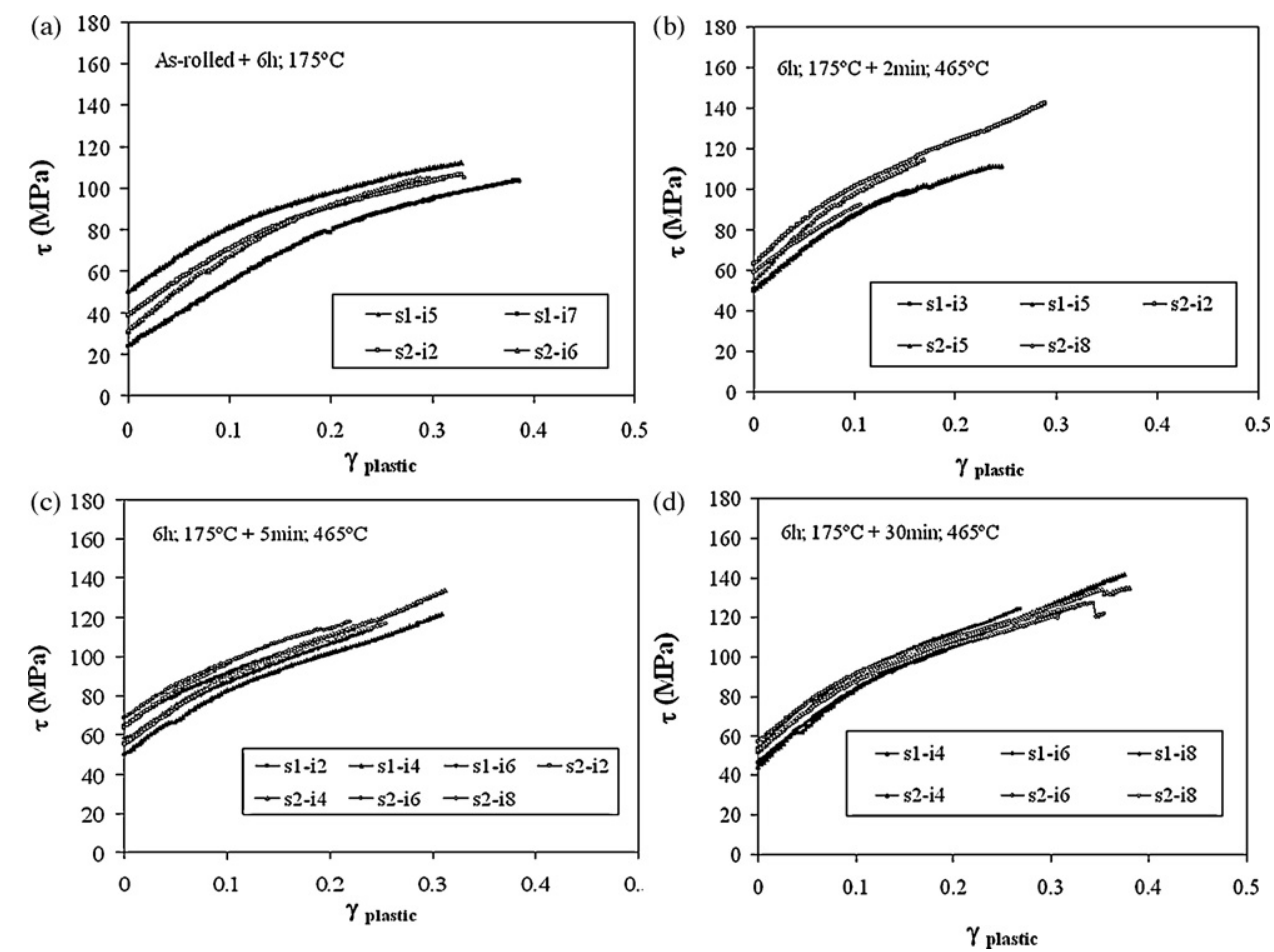

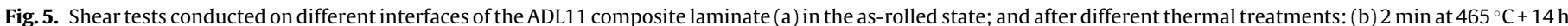
at $133^{\circ} \mathrm{C}$; (c) $5 \mathrm{~min}$ at $465^{\circ} \mathrm{C}+14 \mathrm{~h}$ at $133^{\circ} \mathrm{C}$; (d) $30 \mathrm{~min}$ at $465^{\circ} \mathrm{C}+14 \mathrm{~h}$ at $133^{\circ} \mathrm{C}$.

(CuFeMn) $\mathrm{Al}_{6}$, (CuFeMn) $)_{3} \mathrm{Si}_{2} \mathrm{Al}_{15}$. Thus, it is our contention that during solution treatment, copper atoms could diffuse towards insoluble intermetallic inclusions. Furthermore, a previous investigation [23] showed that at high temperature, as that considered during solution treatment, Cu segregates to interfaces, grain boundaries and dislocations resulting in a smaller amount of $\mathrm{Cu}$ in solid solution able to form effective hardening precipitates, especially at longer solution times. This effect is specially striking for the Al2024, which is hardened by $\mathrm{CuAl}_{2}$ and $\mathrm{Al}_{2} \mathrm{CuMg}$ precipitates.

\subsubsection{Shear tests}

In order to quantify the mechanical properties (strength and ductility) of the interfaces, shear tests along them have been performed (Fig. 5 and Table 4). The objective is to correlate the interfacial mechanical properties with the microstructure of the adjacent aluminium alloys, as a function of the solution treatment time. Fig. 5 shows stress-plastic strain curves obtained from shear tests on the interfaces for the as-rolled ADL11 composite laminate (Fig. 5a), and for the T6 treated composite laminate subjected to different solution treatment times (Fig. 5b-d). Table 4 includes values of mechanical properties extracted from each shear curve and average values for each temper condition. Several samples for every thermal treatment were tested. Hence, the interfaces in the composite laminate are labelled by numbers indicating their location in the composite laminate in respect to the outer layer (e.g. s2-i5 means sample 2 and the fifth interface from the surface). For comparison, shear mechanical properties of the as-received aluminium alloys are also included in Table 4 . The maximum shear stress of the $\mathrm{Al} 7075$ and $\mathrm{Al} 2024$ alloys is 279 and $236 \mathrm{MPa}$, respectively, and the plastic shear deformation is 0.8 and 1.2. Regarding the ADL11 composite laminate, in all cases, fracture occurred at the point of maximum stress to failure with instantaneous debonding at interface, as indicated by abrupt unloading on the force-displacement curves shown in Fig. 5. In general, the interfaces required some plastic deformation prior to fracture for the as-rolled and treated ADL11 composite laminate, being these weaker (about half) than the con- stituent aluminium alloys (Table 4). Results included in Fig. 5 and Table 4 show some influence of the heat treatment on the interfacial shear strength and ductility. Laminate interfaces are quite brittle, with values of maximum shear stress between $107 \mathrm{MPa}$ for the as-rolled ADL11 composite laminate, and 129 MPa for the ADL11 composite laminate solutioned for $30 \mathrm{~min}$; and values of plastic shear deformation to failure between 0.19 for the ADL1 1 composite laminate solutioned for $2 \mathrm{~min}$ and 0.34 for the as-rolled composite laminate. Shear strength requirements for bonds in aircraft structures are generally much lower (10-20 MPa) than those observed in the present work [28]. The shear toughness of the interfaces was measured as the area under the load-displacement curve. Average interfacial shear toughness between $7.4 \mathrm{~kJ} / \mathrm{m}^{2}$ for the ADL11 composite laminate solutioned for $2 \mathrm{~min}$, and $12.8 \mathrm{~kJ} / \mathrm{m}^{2}$ for the material solutioning for $30 \mathrm{~min}$ was calculated. Interfaces of T6 treated samples showed higher yield shear strength and maximum shear stress to failure than those for the as-rolled composite laminate, as a consequence of the thermal treatment (precipitation hardening). Furthermore, the maximum yield strength calculated from the shear curves was for interfaces in the ADL11 composite laminate solution treated for $5 \mathrm{~min}$, according to microhardness measurements for the constituent aluminium alloys (Fig. 4). These results indicate the correlation of the mechanical properties of the adjacent materials with the interfacial behaviour. It is worth noting that since the interface is the same for all specimens, as only one multilayer ADL11 composite laminate has been processed, the interfacial toughness enhancement with increasing solution treatment time is due to the influence of this parameter on the plasticity of the adjacent aluminium alloys, and the ability of the interface to accommodate that deformation [29]. Therefore, for a given interface and processing, the evolution of the shear strength and ductility during different solution treatments is controlled by the plastic properties of the matrix of the adjacent aluminium alloys. In addition, the evolution of yield stress (plastic properties) of the aluminium matrix during thermal treatment is mainly controlled by the hardening precipitates and the grain size. 
Table 4

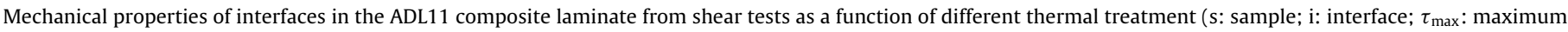
shear strength; $\tau_{\mathrm{YS}}$ : yield point; $\gamma_{\text {plastic max }}$ : maximum plastic shear strain; $A$ : area under shear load-displacement curve).

\begin{tabular}{|c|c|c|c|c|c|}
\hline Temper & Sample & $\tau_{\mathrm{YS}}(\mathrm{MPa})$ & $\tau_{\max }(\mathrm{MPa})$ & $\gamma_{\text {plastic max. }}$ & $A\left(\mathrm{~kJ} / \mathrm{m}^{2}\right)$ \\
\hline \multicolumn{6}{|l|}{ As-received Al 7075-T6 } \\
\hline Average & & 212 & 279 & 0.82 & 96 \\
\hline \multicolumn{6}{|l|}{ As-received Al 2024-T3 } \\
\hline Average & & 154 & 236 & 1.2 & 101 \\
\hline \multirow[t]{4}{*}{ As-rolled ADL11 $+6 \mathrm{~h}-175^{\circ} \mathrm{C}$} & s1-i5 & 51 & 112 & 0.33 & 11.6 \\
\hline & s1-i7 & 24 & 104 & 0.39 & 10.2 \\
\hline & $\mathrm{s} 2-\mathrm{i} 2$ & 39 & 106 & 0.33 & 10.2 \\
\hline & s2-i6 & 32 & 105 & 0.29 & 8.5 \\
\hline Average & & 37 & 107 & 0.34 & 10.1 \\
\hline \multirow[t]{5}{*}{$\mathrm{ADL} 11+6 \mathrm{~h}-175^{\circ} \mathrm{C}+2 \mathrm{~min}-465^{\circ} \mathrm{C}$} & s1-i3 & 50 & 99 & 0.15 & 5.2 \\
\hline & s1-i5 & 51 & 111 & 0.24 & 8.7 \\
\hline & s2-i2 & 63 & 142 & 0.29 & 12.5 \\
\hline & s2-i5 & 55 & 114 & 0.17 & 6.3 \\
\hline & s2-i8 & 59 & 92 & 0.11 & 4.5 \\
\hline Average & & 56 & 111 & 0.19 & 7.4 \\
\hline \multirow[t]{7}{*}{$\mathrm{ADL} 11+6 \mathrm{~h}-175^{\circ} \mathrm{C}+5 \mathrm{~min}-465^{\circ} \mathrm{C}$} & $\mathrm{s} 1-\mathrm{i} 2$ & 65 & 102 & 0.16 & 6.6 \\
\hline & s1-i4 & 51 & 122 & 0.31 & 10.9 \\
\hline & s1-i6 & 58 & 117 & 0.25 & 9.5 \\
\hline & $\mathrm{s} 2-\mathrm{i} 2$ & 65 & 97 & 0.10 & 4.7 \\
\hline & s2-i4 & 57 & 133 & 0.31 & 12.4 \\
\hline & s2-i6 & 69 & 118 & 0.22 & 9.8 \\
\hline & s2-i8 & 56 & 117 & 0.25 & 9.6 \\
\hline Average & & 60 & 115 & 0.23 & 9.1 \\
\hline \multirow[t]{6}{*}{$\mathrm{ADL} 11+6 \mathrm{~h}-175^{\circ} \mathrm{C}+30 \mathrm{~min}-465^{\circ} \mathrm{C}$} & s1-i4 & 45 & 142 & 0.37 & 14.1 \\
\hline & s1-i6 & 54 & 124 & 0.27 & 10.1 \\
\hline & s1-i8 & 47 & 127 & 0.33 & 12.1 \\
\hline & s2-i4 & 52 & 135 & 0.38 & 14.9 \\
\hline & s2-i6 & 57 & 127 & 0.34 & 14.0 \\
\hline & s2-i8 & 53 & 120 & 0.31 & 11.4 \\
\hline Average & & 51 & 129 & 0.33 & 12.8 \\
\hline
\end{tabular}

The interfaces in the as-rolled ADL11 composite laminate have shown a lower yield stress (Fig. 5) than for the heat treated materials, due to coarse precipitates formed in grain boundaries and on the dispersoids during a slow cooling, reducing significantly the shear stress required to initiate plastic deformation (Table 4), often associated with higher ductility and enhanced intrinsic toughness. As a consequence, the interfaces in the as-rolled composite laminate showed an average interfacial toughness similar to the interfaces in the peak-aging condition, Fig. 5c. On the other hand, the ADL11 composite laminate solutioning for 2 min presented the lowest mean interfacial toughness. It is possible that a higher intrinsic defect population, as grain boundaries or internal stresses at the interface for shorter solution treatment, will reduce the failure strength. In this regard, this treated sample showed the finest grains around the interface, high Vickers microhardness and longer diffusion distance (i.e. larger hardened area) than the ADL11 composite laminate solutioned for $30 \mathrm{~min}$. Therefore, the increase in shear toughness as a function of the solution treatment can be attributed to an improvement in interfacial mechanical strength and the plasticity of the adjacent aluminium alloys for prolonged solution times. The increase in solution time produced a pronounced abnormal grain size in the $\mathrm{Al} 2024$ alloy, which spreads towards the interface (Fig. 2), and normal grain growth in the Al 7075 alloy. Additionally, the increase in solution treatment time up to 30 min produces a decrease in Vickers microhardness due to solid solution depletion to intermetallic particles, grain boundaries, dislocations, etc., decreasing the amount of $\mathrm{Cu}$ in solid solution available for precipitation hardening. Therefore, both the grain size increase and the lower precipitation hardening justifies the increase in ductility of the aluminium alloys adjacent to the interface, allowing higher plastic deformation and higher ability of the interface to accommodate deformation, i.e., interfacial toughness.

Finally, in all shear tests the locus of failure was interfacial, which corresponds to a localization of the crack at the interface. Fig. 6 shows SEM micrographs at two magnifications of fractured surfaces from shear tests for the as-rolled and T6 treated ADL11 composite laminate solutioned for different times. Microscopic features on the interfacial fracture surface show good bonding and evidence of high plastic deformation on the aluminium alloys. Additionally, the influence of the mechanical properties of the aluminium alloys adjacent to the interface is clearly visible. For the as-rolled ADL11 composite laminate (Fig. 6a and b), ductile intergranular (or inter-subgranular) fracture is observed, showing the initial grain structure. The coarse constituent particles, produced as a consequence of slow cooling after processing, act as initiation sites for damage. Toughness has been experimentally observed to decrease when the volume fraction of coarsened constituent particles increases [25].

On the other hand, the T6 thermal treatment influences the plastic behaviour of the grains. Fig. $6 c$ shows the SEM micrographs at low magnification of the interfacial fracture surface of the ADL11 composite laminate solutioned for $2 \mathrm{~min}$, where a smooth surface can be observed, showing very little plastic deformation. Higher magnification allows observing again the grain microstructure through intergranular fracture mode. The appearance of the intergranular fracture is related to the precipitation on grain boundaries 

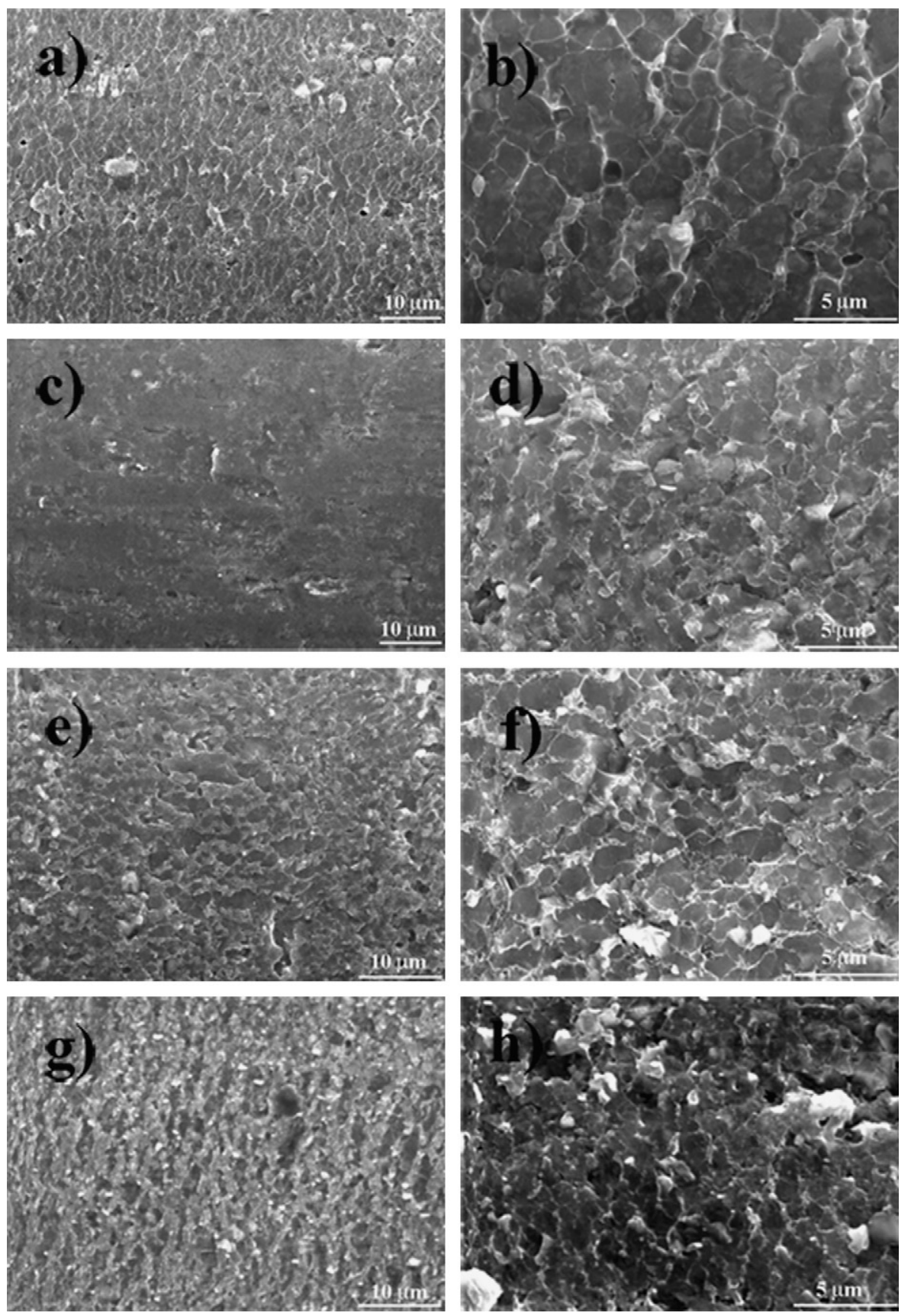

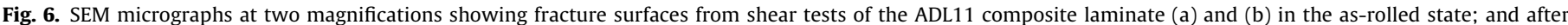
different thermal treatments: (c) and (d) $2 \mathrm{~min}$ at $465^{\circ} \mathrm{C}+14 \mathrm{~h}$ at $133^{\circ} \mathrm{C}$; (e) and (f) $5 \mathrm{~min}$ at $465^{\circ} \mathrm{C}+14 \mathrm{~h}$ at $133^{\circ} \mathrm{C}$; (g) and (h) $30 \mathrm{~min}$ at $465^{\circ} \mathrm{C}+14 \mathrm{~h}$ at $133^{\circ} \mathrm{C}$.

which reduces their cohesion, and to the development of a soft precipitation free zone, PFZ, which promotes strain localization in the grain boundary vicinity $[25,30]$. Thus, this fracture mode implies an influence on plastic behaviour (yield stress and work hardening capacity) of the grains of the constituent material, as well as of the intrinsic strength of the grain boundaries.

The increase in solution treating time (for $5 \mathrm{~min}$, Fig. 6e and $\mathrm{f}$, or $30 \mathrm{~min}$ Fig. $6 \mathrm{~g}$ and $\mathrm{h}$ ) produces an improvement in interfacial toughness and thus higher bonding degree, which is reflected in the shear fracture surface showing an increase of the amount of intergranular fracture, even observed at low magnification. Plastic tearing is more evident for solution time of $30 \mathrm{~min}$.

In summary, the microstructure and mechanical properties of the aluminium alloys adjacent to the interface affects the interface toughness and its locus of failure.

\section{Conclusions}

In the present work, the microstructure in the bonding region and the interfacial mechanical properties of a multilayer laminate based on $\mathrm{Al} 7075$ and $\mathrm{Al} 2024$ alloys have been characterized, as a function of different thermal treatments.

Accordingly, the rise of interfacial toughness with increasing solution treatment time can be attributed to an improvement in interfacial mechanical strength and the progressive increase in ductility for prolonged solution times of the adjacent aluminium alloys. This increase in ductility is associated with normal grain growth in the $\mathrm{Al} 7075$ by recovery, and abnormal grain growth for the $\mathrm{Al}$ 2024 by migration of non-equilibrium grain boundaries towards the interface. Additionally, the increase in solution treatment time produces solid solution depletion to intermetallic particles, grain 
boundaries, dislocations, etc., decreasing the amount of solid solution available for precipitation hardening. Therefore, both the grain size increase and the lower precipitation hardening for prolonged solution treatment times justifies the increase in ductility of the aluminium alloys adjacent to the interface, allowing higher plastic deformation and higher ability of the interface to accommodate deformation, i.e., interfacial toughness.

\section{Acknowledgements}

Financial support from CICYT (Project MAT2003-01172 and MAT2006-11202) is gratefully acknowledged. C.M. CepedaJiménez thanks the Spanish National Research Council (CSIC) for a I3P contract. We also thank F.F. González-Rodríguez for assistance during hot rolling. Finally, an especial mention in memory of P.J. González-Aparicio for his help and assistance with electron microscopy during all these years is made.

\section{References}

[1] M.E. Launey, R.O. Ritchie, Adv. Mater. 21 (2009) 1-8.

[2] C.M. Cepeda-Jiménez, J.M. García-Infanta, M. Pozuelo, O.A. Ruano, F. Carreño, Scripta Mater. 61 (2009) 407-410.

[3] C.M. Cepeda-Jiménez, M. Pozuelo, J.M. García-Infanta, O.A. Ruano, F. Carreño, Metall. Mater. Trans. A 40 (2009) 69-79.

[4] H. Danesh Manesh, H.Sh. Shahabi, J. Alloy Compd. 476 (2008) 292-299.

[5] M.Z. Quadir, A. Wolz, M. Hoffman, M. Ferry, Scripta Mater. 58 (2008) 959-962.

[6] G.P. Chaudhari, V. Acoff, Compos. Sci. Technol. 69 (2009) 1667-1675.

[7] J. Zhang, J.J. Lewandowski, J. Mater. Sci. 29 (1994) 4022-4026.

[8] S. Nambu, M. Michiuchi, J. Inoue, T. Koseki, Compos. Sci. Technol. 69 (2009) 1936-1941.
[9] A.G. Evans, J.W. Hutchinson, Acta Metall. Mater. 43 (1995) 2507-2530

[10] M.S. Hu, A.G. Evans, Acta Metall. 37 (1989) 917-925.

[11] K.J.M. Papis, B. Hallstedt, J.F. Löffler, P.J. Uggowitzer, Acta Mater. 56 (2008) 3036-3043.

[12] A. Deschamps, S. Ringeval, G. Texier, L. Delfaut-Durut, Mater. Sci. Eng. A517 (2009) 361-368.

[13] N. Kamikawa, N. Tsuji, X. Huang, N. Hansen, Acta Mater. 54 (2006) 30553066.

[14] J.E. Hatch (Ed.), Aluminium: Properties and Physical Metallurgy, ASM, Metals Park, Ohio, 1984.

[15] C.M. Cepeda-Jiménez, R.C. Alderliesten, O.A. Ruano, F. Carreño, Compos. Sci. Technol. 69 (2009) 343-348.

[16] G.E. Dieter, Mechanical Metallurgy, SI Metric, UK, 1988, pp. 12-15

[17] C.E. Campbell, L.A. Bendersky, W.J. Boettinger, R. Ivester, Mater. Sci. Eng. A 430 (2006) 15-26.

[18] Y. Xue, H. El Kadiri, M.F. Horstemeyer, J.B. Jordon, H. Weiland, Acta Mater. 55 (2007) 1975-1984.

[19] M.Z. Quadir, O. Al-Buhamad, L. Bassman, M. Ferry, Acta Mater. 55 (2007) 5438-5448.

[20] F.J. Humphreys, M. Hatherly, Recrystallization and Related Annealing Phenomenon, 2nd ed., Elsevier, 2004.

[21] R.K. Islamgaliev, N.F. Yunusova, I.N. Sabirov, A.V. Sergueeva, R.Z. Valiev, Mater. Sci. Eng. A 319-321 (2001) 877-881.

[22] H. Jazaeri, F.J. Humphreys, Acta Mater. 52 (2004) 3239-3250.

[23] J.P. Lokker, A.J. Böttger, W.G. Sloof, F.D. Tichelaar, G.C.A.M. Janssen, S. Radelaar, Acta Mater. 49 (2001) 1339-1349.

[24] J. Dennis, P.S. Bate, F.J. Humphreys, Acta Mater. 57 (2009) 4539-4547.

[25] D. Dumont, A. Deschamps, Y. Brechet, Mater. Sci. Eng. A 356 (2003) 326336.

[26] B. Verlinden, P. Wouters, H.J. McQueen, E. Aernoudt, L. Delaey, S. Cauwenberg, Mater. Sci. Eng. A123 (1990) 229-237.

[27] Z. Huda, N.I. Taib, T. Zaharinie, Mater. Chem. Phys. 113 (2009) 515-517.

[28] Y. Huang, N. Ridley, F.J. Humphreys, J.-Z. Cui, Mater. Sci. Eng. A 266 (1999) 295-302.

[29] J.W. Hutchinson, A.G. Evans, Acta Mater. 48 (2000) 125-135.

[30] A. Deschamps, G. Texier, S. Ringeval, L. Delfaut-Durut, Mater. Sci. Eng. A 501 (2009) 133-139. 